\title{
Time-of-Flight Secondary Ion Mass Spectrometry Imaging of Cross- Sections from the Bacchanals Paintings of Nicolas Poussin
}

\author{
Caroline Bouvier ${ }^{1}$, Helen Glanville ${ }^{1}$, Laurence de Viguerie ${ }^{1}$, Chiara Merucci ${ }^{2}$, Philippe Walter ${ }^{1}$, and \\ Alain Brunelle 1* $^{*}$ \\ ${ }^{1}$ Sorbonne Université, CNRS, Laboratoire d'Archéologie Moléculaire et Structurale, LAMS, 4 place Jussieu, 75005 Paris, \\ France \\ ${ }^{2}$ Museo Nazionale d'Arte Antica, Palazzo Barberini, Via delle Quattro Fontane, 13, 00184 Roma, Italy \\ * Corresponding Author: E-mail: Alain.Brunelle@cnrs.fr
}

\begin{abstract}
The two paintings Infant Bacchanals (Museo Nazionale d'Arte Antica, Palazzo Barberini, Rome, Italy) executed by Nicolas Poussin (Les Andelys, 1594 - Rome, 1665) in around 1626, are thought to have been painted "a guazzo", which means either with a glue or with an egg binding medium. To date, this has never been confirmed through analysis. Dual beam Time-of-Flight Secondary Ion Mass Spectrometry (TOF-SIMS), using a bismuth cluster liquid metal ion gun and an argon gas cluster ion beam, allows the mapping of organic and inorganic matter on paintings cross-sections, with the possibility to acquire sub-micrometer resolution mass spectrometry images of the sample, together with high mass resolution by using a delayed extraction of secondary ions. The surfaces of cross-sections from both paintings were prepared beforehand either by polishing or microtome cutting, and then cleaned with the gas cluster ion beam directly inside the vacuum chamber of the instrument. The nature of the binders in the two paintings was investigated by TOF-SIMS analyses. By considering the uneven physical properties of the heterogeneous analysed surfaces, several high-resolution images were recorded with different instrument settings. The detection of lipids seems to point towards an oil containing medium, rather than a glue-binding medium. An emulsion made of oil and glue is another hypothesis to be explored to better understand the artist's working methods in his early career.
\end{abstract}

A painting is made of a support covered with one or more preparation layers, above which pictorial layers containing pigments in organic binder(s) are applied to achieve the optical effects sought by the painter. An organic varnish sometimes covers the whole. Analysing such an object comes with constraints since the material itself is a layered heterogeneous mixture of compounds that have interacted with each other in uncontrolled environments over centuries. TOF-SIMS imaging allows the mapping of these compounds to bring out indications relating to their nature, origin or state of preservation. ${ }^{1,2,3,4,5,6}$ Not only can TOF-SIMS imaging give the localisation and identification of pigments, in the same way as SEM-EDX, ${ }^{4,7}$ but it can also localise and identify organic material, such as the painting medium and the varnish.

Two paintings with the title Infant Bacchanals (Figure 1) hang alongside each other in the Museo Nazionale d'Arte Antica, Palazzo Barberini, Rome, Italy. They represent two bacchanalian scenes, which are Roman religious celebrations in honour of Bacchus (Dionysus in Greek), god of wine and fertility. Nicolas Poussin (Les Andelys, 1594 - Rome, 1665) painted both around 1626, shortly after arriving in Rome, which makes them the earliest of his known works to have been executed in Italy. The colours have chalky unsaturated finish similar to fresco, an effect most likely sought by the artist, perhaps by the means of a lean medium, ${ }^{8}$ giving the roughness needed to scatter incident light. His friend and biographer Giovanni Pietro Bellori (who wrote Le vite de' pittori, scultori e architettimoderni, 1672), ${ }^{9}$ mentions "Bacchanal paintings" painted at this time with the painting technique "a guazzo" - that is pigments bound with glue or egg rather than oil. Both the paintings were also lined (with an animal glue paste, characteristic of Italian lining techniques) onto new canvas in the past, which adds further complexity to the analyses. The two paintings in Palazzo Barberini are thought to be the ones cited by Bellori; however, the painting technique has never been verified through analysis.

Cross-sections are highly suited for a simultaneous analysis of all the layers of a painting: a sub-millimetre scale sample is removed with a blade with the aid of a binocular magnifier. Such samples are small and fragile, in addition to being rare and unique and are embedded in resin blocks in order to be able to cut them to expose their layer structure. Even if the sampling step is invasive, the purpose is to keep the cross-section as intact as possible to allow subsequent analyses with different techniques.

TOF-SIMS is a surface-sensitive analytical method requiring the sample surface to be flat and clean, because the mass spectrum quality depends on it. If the surface is contaminated, for example by exogenous lipids, hydrocarbons and/or silicones (in particular, polydimethylsiloxane [PDMS]), the ions detected will mostly come from these compounds, which can obscure the ion signal expected from the sample itself, if one of them creates a matrix effect. Moreover, if the surface has irregularities (protruding grains, porosity, steps, etc.), the secondary ions will be formed at different distances from the extractor, which will widen the ion peaks, or even lead to loss of signal. Microtome cutting has proven to be an effective way to achieve this, but it is a long and delicate step. ${ }^{10}$ 
The TOF-SIMS mass spectrometer used here is equipped, in addition to the Liquid Metal Ion Gun as a primary ion source, with an argon Gas Cluster Ion Beam (GCIB). The latter allows a gentle sputtering of the surface without damaging the underlying layers. In addition, the time-of-flight analyser is equipped with delayed extraction of secondary ions, which offers the possibility of coupling a spatial resolution down to $400 \mathrm{~nm}$, with a mass resolution of a few thousand. ${ }^{11}$ The abrasion capabilities of the surface using GCIB were compared to the microtome cutting and dry polishing, and the data quality was assessed.

A new and dramatic improvement of method of data acquisition was implemented and is described: small areas having uneven physical surface properties were analysed one after the other by optimizing the mass spectrometer settings for each one, and thus maximizing the secondary ion collection.

TOF-SIMS analyses were carried out on samples from the two paintings in order to bring new insights into Poussin's working methods. More specifically, the binding medium of each layer was investigated: given the common paint practices at that time, it can be either oil, purely lipidic, egg yolk, containing both lipids and protein, or glue, which is also a proteinaceous material. The main question is to determine if lipids are present in the pigmented layer, and if so, to distinguish between drying oil and egg yolk. In order to do this, amino acid fragments are looked for to deduce the presence of proteinaceous materials. Establishing if the Infant Bacchanals were painted with or without oil will help the further understanding of the history and development of painting techniques. Moreover, the analysis of these two samples from two related paintings also makes it possible to compare the two preparatory layers, demonstrating similarities and differences.

\section{MATERIALS AND METHODS}

The cross-sections were sampled on the edge of the paintings. The one from the "small" Bacchanal and the one from the "big" one, will be herein after be referred to as Pp1 and Pg3, respectively (Figure 1). Both samples were embedded in a polyester resin (SODY-33, ESCIL). By polishing it from the side a crosssection of all the layers is apparent on the surface, thus allowing the imaging of all the layers at one and the same time.

Pp1 was sampled on the greenish ground near the foot of the Putto turning its back. The main part of the cross-section is a light brown-yellow layer containing canvas fibres (rounded shapes) mixed with a priming lightly tinted with fine red particles. The resin has noticeably infiltrated this layer, which has also split into two. The broken part, however, seems browner, suggesting a difference in composition. Above this is the green layer where large, well defined bottle-green ovoid particles (about $50 \mu \mathrm{m}$ ) are discerned in a paler green layer containing whitish areas and grains of various colours (yellow, red, black). At the extreme surface of the painting lies a light brown transparent layer about $10 \mu \mathrm{m}$ thick, seemingly composed of two superimposed layers, one white and the other transparent. A schematic view of Pp1 sample is shown in Figure 2. Pg3 was sampled on the yellow and greyish plinth at the bottom of the right edge of the painting. This cross-section has no clear stratigraphy, and is very rough. Almost all of it is an off-white mixture with reddish inclusions. Even after the sample preparation, grains of several tens of micrometers outcropped the surface. Moreover, the embedding resin has severely infiltrated the sample. Despite the lower quality of this second sample Pg3, it is still very important to analyse it because sources refer to the two paintings as having been painted by the artist with the same technique and at the same time. ${ }^{9}$ They belong to a homogeneous group regarding the technique used by the painter.

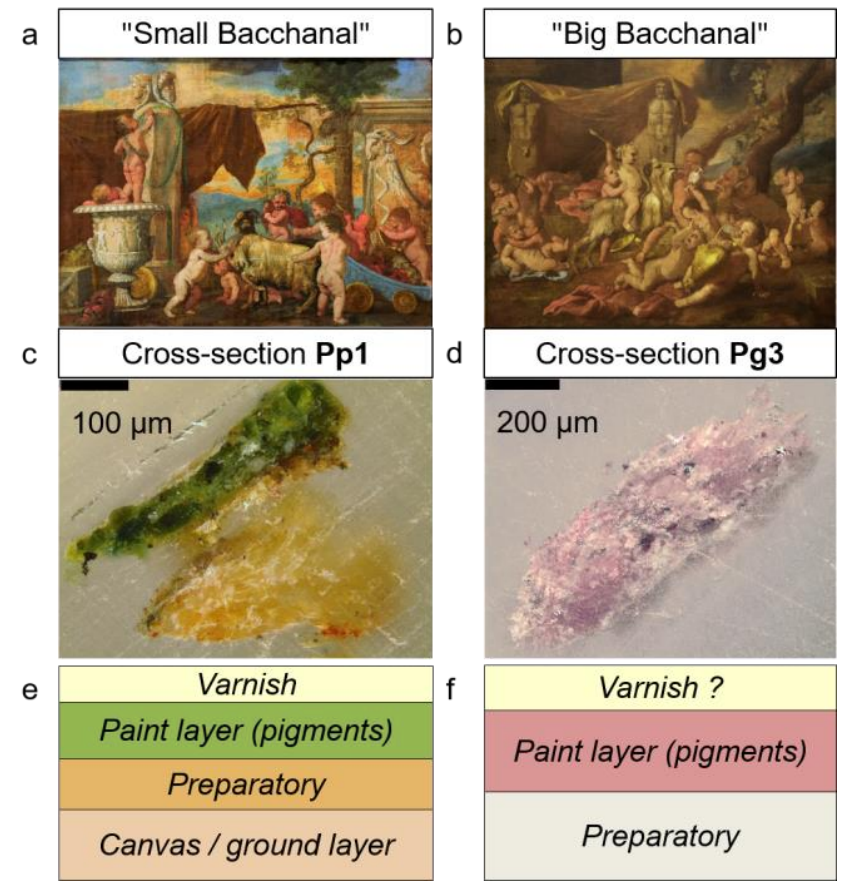

Figure 1: Infant Bacchanals paintings. Nicolas Poussin, painted around 1626, National Gallery of Ancient Art, Palazzo Barberini, Rome, Italy. a: "Small Bacchanal", $56 \mathrm{~cm} \times 76 \mathrm{~cm}$; b: "Big Bacchanal" $74 \mathrm{~cm} \times 84 \mathrm{~cm}$; c: Optical microscopy image of cross section Pp1, embedded in resin, from small Bacchanal. Scale bar 100 $\mu \mathrm{m}$; d: Optical microscopy image of cross section Pg3, embedded in resin, from big Bacchanal. Scale bar $200 \mu \mathrm{m}$; e and f: Schematic views of the layers in the cross sections $\mathrm{c}$ and $\mathrm{d}$, respectively. Painting photographs: Copyright A. Brunelle and courtesy of Museo Nazionale d'Arte Antica.

Because the sample had previously been prepared for SEM analysis, the surfaces were coated with amorphous carbon. To obtain new and clean surfaces, they were prepared either by polishing with a micromesh cloth grit 6000 (Sonus Music supply), or by removing 5 micrometer thick sections with a microtome (HistoCore Multicut R, Leica, France) equipped with a tungsten carbide knife. The surface of the block was then directly analysed. The quality of the data obtained after these surface preparation steps was compared in Table S1 and Figure S1. Microscopic images of both samples were recorded before and after analysis using an optical microscope (Olympus BX51, Rungis, France) equipped with a motorized scanning stage (Marzhauser Wetzlar GmbH, Wetzlar, Germany), a SC30 colour camera, and monitored by the Olympus Stream Motion 1.9 software. Extended focal imaging (EFI) scanning mode was applied to improve the image quality.

The TOF-SIMS analyses were carried out on a TOF-SIMS IV (IONTOF GmbH, Germany) in the Laboratory of Molecular and Structural Archaeology (LAMS, CNRS - Sorbonne University, Paris, France). The raw data were acquired using SurfaceLab 6.7 software (IONTOF GmbH, Germany) and 
processed with the later version SurfaceLab 7.0 after conversion of all the raw files.

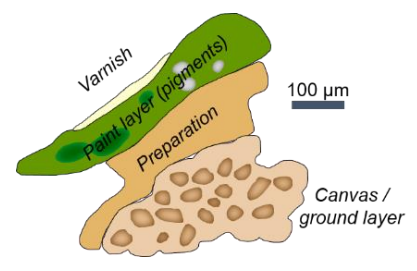

Figure 2: Schematic top view of cross-section Pp1 and layers in it, embedded in resin SODY-33 and polished.

Once the sample is placed in the instrument, with the surface perpendicular from the extractor axis, the GCIB allows a smooth sputtering of the surface without damaging the underlying layers. The beam was chosen to emit $2000 \mathrm{Ar}$ atoms clusters with a kinetic energy of $10 \mathrm{keV}$ (each atom bears $5 \mathrm{eV}$ ), and lateral size of the sputtered area was selected to be more than twice that of the area analysed. The contaminated surface was sputtered this way. The peak of the $\mathrm{SiC}_{3} \mathrm{H}_{9}{ }^{+}$positive ion $(\mathrm{m} / \mathrm{z}$ 73.05) from PDMS was used to monitor the removal of the polluted surface.

In addition to cross-sections, several reference samples of pigments and binders were analysed (see supporting information Figures S2 to S8 and Tables S2 to S6). Comparisons will be presented between the painting samples and the characteristic ion peaks from these reference samples.

\section{ANALYTICAL OPTIMISATION}

The TOF-SIMS primary ion source used for analysis is a liquid metal ion gun delivering a bismuth cluster pulsed ion beam $(25$ $\mathrm{keV}$ energy $\mathrm{Bi}_{3}{ }^{+}$ions) hitting the surface with an incidence angle of $45^{\circ}$. A low energy electron flood gun is used between each analysis scan to neutralise the surface. In addition, when these thick samples are submitted to the extractor electrostatic field, they behave as a dielectric and a potential builds up on their surfaces. This unknown potential is dependent on the dielectric properties and on the thickness. As a result, the secondary ions undergo a fixed extraction voltage lowered by this surface potential, and therefore no longer have the expected kinetic energy of $2 \mathrm{keV}$. Since the ion path in the analyser is tuned for secondary ions having this kinetic energy, it must be corrected according to the actual energy of the secondary ions to avoid both loss of transmission and resolution. This compensation method has already been described in detail elsewhere. ${ }^{12}$ It is very important to keep in mind that this is inherent to all insulating surfaces and does not depend on the charge compensation by the electron flood gun, the latter only avoiding surface charging during the analysis. Here, for the resin embedded sample, this tuning demonstrates the kinetic energies of the secondary ions were around $1.6 \mathrm{keV}$ instead of $2 \mathrm{keV}$. The resin and the different layers of the samples also have diverse permittivity, and have therefore different surface potential values. It is then recommended to compensate with the exact potential of the area of interest, just before each acquisition, so that the parameters of the analyser can be tuned accordingly. Otherwise, there might be a selective loss of signal depending on the settings used. If the analysed surface is so inhomogeneous as to have dramatically different dielectric properties, then the only way is to reduce the analysed area into several smaller ones, each having its own proper tunings.

In this work most of the analyses were made using the so-called "burst alignment with delayed extraction" (BA+DE) focusing mode, in which the beam diameter can be reduced down to 400 $\mathrm{nm}$. In this mode the long primary ion pulses $(\sim 100 \mathrm{~ns})$ are compensated by a delayed extraction (DE) of the secondary ions, as described in full detail by Vanbellingen et al. ${ }^{11}$ This delayed extraction weakens the dependence of mass resolution from the pulse width, enabling one to obtain ion images having both high mass and spatial resolutions. The "high current bunched" (HCBU) mode in which primary ions are bunched in pulses of less than $1 \mathrm{~ns}$ has also been used in some cases. It enables high mass resolution $(\mathrm{M} / \Delta \mathrm{M}$, full width at half maximum, of a few thousands), with a beam diameter of 2-3 micrometers, limiting spatial resolution, but with a primary ion current of $0.4 \mathrm{pA}$ (at a frequency of $10 \mathrm{kHz}$ ) instead of $0.08 \mathrm{pA}$ in the case of the $\mathrm{BA}+\mathrm{DE}$ mode.

Several ion images were acquired in BA+DE mode. Firstly, dual beam images in both polarities of the whole sample were recorded. Areas of $400 \mu \mathrm{m} \times 400 \mu \mathrm{m}$ were analysed choosing a number of pixels of $1024 \times 1024$ so as to have a pixel size equal to $390 \mathrm{~nm}$ (because this pixel size is approximately equal to the primary ion beam size). ${ }^{11}$ The $\mathrm{Bi}_{3}{ }^{+}$primary dose was $5.10^{12}$ ions $/ \mathrm{cm}^{2}$. A millimeter square around the cross-section was cleaned with a dose of $1.10^{15}$ ions $/ \mathrm{cm}^{2}$ using $10 \mathrm{keV}$ argon clusters of 2000 atoms prior to analysis, and soft sputtering runs $\left(10^{14}\right.$ ions $\left./ \mathrm{cm}^{2}\right)$ were made between each analysis scan. The measured mass resolution was 3600 and 3000 for $m / z 208$ for positive and negative ion modes, respectively. The heterogeneity of the surface might limit the mass resolution and preventing from optimum secondary ion transmission. Cross-sections heterogeneity must be taken into consideration in order to optimize the transmission of all ion species. To adapt the surface potential compensation to the area analysed, smaller surface images were recorded: $100 \mu \mathrm{m} \times 100 \mu \mathrm{m}$ to $250 \mu \mathrm{m} \times 250 \mu \mathrm{m}$ areas, with pixel sizes of $390 \mathrm{~nm}$ to $585 \mathrm{~nm}$, and primary doses between $5.10^{11}$ ions $/ \mathrm{cm}^{2}$ and $1.10^{12}$ ions $/ \mathrm{cm}^{2}$. For these small image areas, a millimeter square around the cross-section surface was cleaned prior to analysis with a dose of $10^{14} \mathrm{ions} / \mathrm{cm}^{2}$ using $10 \mathrm{keV}$ argon clusters of 2000 atoms.

The surface prepared with the microtome was imaged using the $\mathrm{BA}+\mathrm{DE}$ mode, again in both polarities. Both sample surfaces were cleaned over a millimeter square around the cross-section surface prior to analysis with a dose of $10^{14} \mathrm{ions} / \mathrm{cm}^{2}$ using $10 \mathrm{keV}$ argon clusters of 2700 atoms. For the sample Pp1, areas of $200 \mu \mathrm{m} \times 200 \mu \mathrm{m}$ with pixel size of $390 \mathrm{~nm}$ and primary ion dose of $1.10^{12}$ ions $/ \mathrm{cm}^{2}$ were analysed. For the sample Pg3, areas of $250 \mu \mathrm{m} \times 250 \mu \mathrm{m}$ with pixel size of $489 \mathrm{~nm}$ and primary ion dose of $1.10^{12}$ ions $/ \mathrm{cm}^{2}$ were analysed.

Figure S9 indicates the areas where the different ion images were recorded on the surface of sample Pp1.

When using the BA+DE mode, the relation between the timeof-flight and the square root of $\mathrm{m} / \mathrm{z}$, is not linear anymore. The mass calibration needs to be refined by using ions peaks like $\mathrm{Ca}_{\mathrm{m}} \mathrm{O}_{\mathrm{n}}{ }^{+}$and $\mathrm{Pb}_{\mathrm{m}} \mathrm{O}_{\mathrm{n}}{ }^{+}$in positive ion mode and $\mathrm{Ca}_{\mathrm{n}} \mathrm{O}_{\mathrm{m}}{ }^{-}$and $\mathrm{Pb}_{n} \mathrm{O}_{\mathrm{m}}$ in negative ion mode $(\mathrm{m}>\mathrm{n})$.

The number of detected secondary ions was lowered after each sputtering run during the dual beam acquisitions, and 
cleaning/sputtering with argon affects the measured surface potential. Since the painting cross-sections are made up of various layers with inorganic particles of several tens of microns diameter in diverse overall organic matrices, each compound and mixture have its own sputter yield, leading to an argon-induced roughness because of small height differences (Figure 3). By measuring these gaps, relative sputter yield values could be estimated. The pigment particles stand 1 to $5 \mu \mathrm{m}$ above the organic surrounding level, depending on the layer. This order of magnitude is consistent with an estimation found in the literature. ${ }^{13}$ This phenomenon combined with the heterogeneity of surface potentials can explain why dual beam analysis lead to a loss of transmission for organic ions such as those in the green layer. The gradual modification of the surface state - and thus of the secondary ion transmission - between each analysis scan, raises questions as to the applicability of dual beam imaging with GCIB alone on such heterogeneous insulating materials. However, it still brings the advantage of improving the contrast for inorganic pigments, by summing the signal from successive images, and it is very helpful to image small pigments particles of a few micrometer size, which can hardly be done with only one analysis, even on a very flat surface.

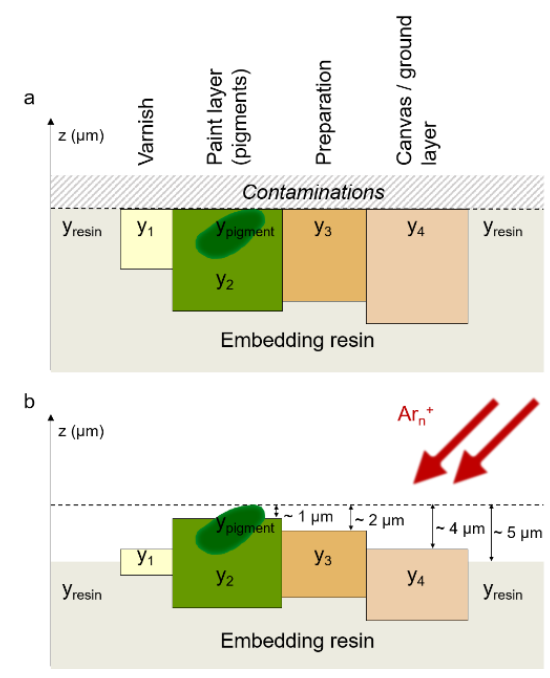

Figure 3: Schematic vertical views of Pp1 cross-section. Each layer is annotated with its own sputter yield value $y_{i}$. a: Before argon cluster sputtering; b: After argon cluster sputtering. The dotted line represents the initial surface height, below the undesirable contamination layer, and the estimated sputtered depths.

It must be noted that when using the dual beam and BA+DE, ion images in negative and positive modes have slight stigmatism differences, making any overlay between the two polarities impossible. On measuring, the negative image was seen to be dilated by about $3 \%$ along one axis compared to the positive one.

\section{RESULTS AND DISCUSSION}

The "Small Bacchanal" sample Pp1. Since the analysed surface is composed of pigment particles of diverse nature in a predominantly organic matrix, a careful examination of the data was carried out by defining several spatial regions of interest (ROI), bringing out ion signals which would otherwise be overwhelmed in the total spectrum.
Embedding resin. The resin mass spectrum was extracted from the total image using a ROI to identify its characteristic ion peaks. The most intense one is assigned to a phthalate (plasticizer) fragment ion $\mathrm{C}_{8} \mathrm{H}_{5} \mathrm{O}_{3}{ }^{+}, \mathrm{m} / z$ 149.04, with some other characteristic ions in positive ion mode $\left(\mathrm{C}_{6} \mathrm{H}_{5}{ }^{+}, \mathrm{m} / z\right.$ 77.04, $\mathrm{C}_{7} \mathrm{H}_{7}{ }^{+}$, $m / z$ 91.07, $\left.\mathrm{C}_{9} \mathrm{H}_{7}{ }^{+}, m / z, 115.06\right)$. The porosity of the painting materials results in an infiltration of the embedding resin into the sample, especially in the preparation layers. Figure 4a shows the images of the $\mathrm{C}_{8} \mathrm{H}_{5} \mathrm{O}_{3}{ }^{+}$ion, $\mathrm{m} / z$ 149.04, and Figure $4 \mathrm{~b}$ shows the image of the $\mathrm{K}^{+}$ion, $m / z, 38.96$, which is omnipresent in the sample and absent from the resin. Figure $4 \mathrm{c}$, which shows the two-colour overlay image between these two ions, allows one to observe where the resin has infiltrated. The resin ion peaks are intense, making it difficult to extract ion images of ions that have an $\mathrm{m} / \mathrm{z}$, ratio close to that of a resin ion. Therefore an ROI was created from the inverse of the image of the $\mathrm{m} / \mathrm{z} 149.04$ ion assigned to $\mathrm{C}_{8} \mathrm{H}_{5} \mathrm{O}_{3}{ }^{+}$. This selection generates a mass spectrum built from the pixels where this ion is not detected, i.e. where the embedding resin is mostly absent.

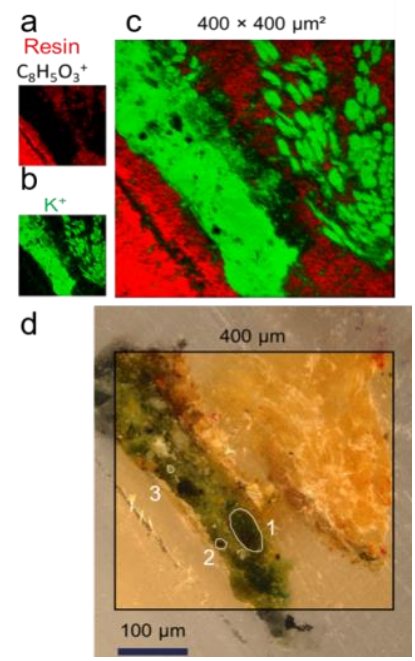

Figure 4: a: Image of the $\mathrm{C}_{8} \mathrm{H}_{5} \mathrm{O}_{3}{ }^{+}$ion, $m / z, 149.04$, characteristic of the phtalates in the resin; $\mathrm{b}$ : Image of the $\mathrm{K}^{+}$ion, $\mathrm{m} / \mathrm{z}$ 38.96, which is detected in the overall sample; c: Two-colour overlay of ion images of a (red) and b (green). Field of view $400 \mu \mathrm{m} \times 400 \mu \mathrm{m}$; $\mathrm{d}$ : Optical microscopy image of the sample Pp1. The black square shows the area analysed by TOF-SIMS. Scale bar $100 \mu \mathrm{m}$. The regions of interest (ROI) mentioned in the text are outlined with a white border. Images recorded in area a (see Figure S9).

Canvas and preparation layer. Several ions characteristic of cellulose detected from this area can be used to help refine the mass calibration. Around the canvas fibres is a preparatory layer of a light brownish colour. An examination of the positive ion mass spectra from ROI drawn in and around the fibres was made to assign ions which are likely to be different amino acid fragments. In addition to reference mass spectra from glues prepared in the laboratory, data from the ION-TOF spectra library included in the SurfaceLab 7 software, and data from the literature were used for comparison. $6,14,15,16$

We observe that the same amino acid fragments are detected in the two samples, indicating the same proteinaceous binder was used in the two paintings. We can thus deduce that the two Infant Bacchanal paintings share the same type of preparation. It must however be kept in mind that the paintings have been 
relined, i.e. a new canvas was attached to the back of the existing one with an animal glue-based adhesive which could also explain the presence of proteins.

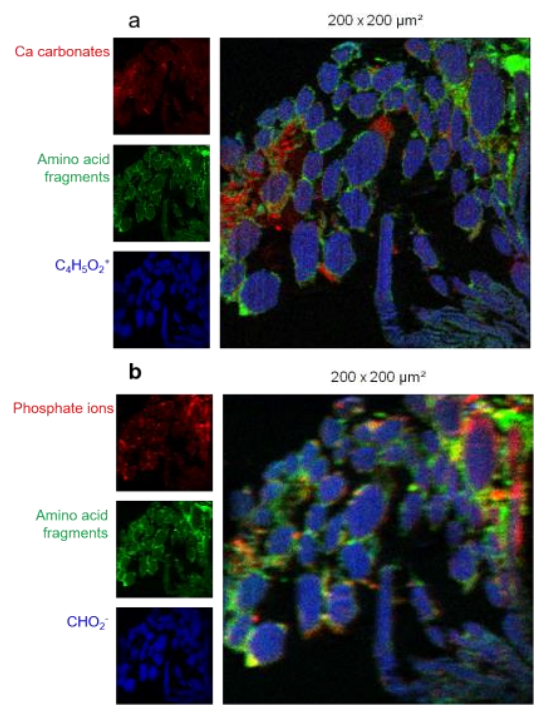

Figure 5: a: Three-colour overlay between ion images of sum of ion images of calcium carbonate ions (red), all detected amino acid fragments (green), and a cellulose fragment ion $\mathrm{C}_{4} \mathrm{H}_{5} \mathrm{O}_{2}{ }^{+} \mathrm{m} / z 85.03$ (blue), all recorded in positive polarity; b: Three-colour overlay between ion images of phosphates (red), amino acid fragments (green), and a cellulose fragment ion $\mathrm{CHO}_{2}{ }^{-}, \mathrm{m} / z 45$ (blue), all recorded in negative polarity. Images recorded in area e (see Figure S9).

Amongst the detected amino acid fragments, some differences were observed between the browner part and the part around the fibres of the preparation layer, suggesting different protein materials may have been used. With the images acquired in $\mathrm{BA}+\mathrm{DE}$ mode in small areas, it is possible to draw a clearer comparison between these two specific regions, because the amino acid fragment ion peaks are more intense and better resolved from other compounds. Table $\mathrm{S} 2$ gives a summary of the detected amino acid fragments in the whole sample according to the layers. The protein material around the fibres (Figure 5) contains Lysine, Proline and Asparagine. In the calcium containing regions, $\mathrm{Ca}^{+},{ }^{44} \mathrm{Ca}^{+}, \mathrm{C}_{\mathrm{n}} \mathrm{H}_{\mathrm{m}} \mathrm{Ca}^{+}, \mathrm{CO}_{2} \mathrm{Ca}^{+}, \mathrm{Ca}_{2} \mathrm{O}^{+}, \mathrm{Ca}_{2} \mathrm{OH}^{+}$, ${ }^{44} \mathrm{CaCaO}^{+}$and $\mathrm{CaCO}_{3} \mathrm{H}^{+}$ions are detected, indicating the presence of calcium carbonate. The sulphate ions in negative ion mode are not localised in these regions. The preparation is therefore made of calcium carbonate mixed with a glue, likely an animal glue, of which the exact origin is with the present analysis not possible to assign with certainty. In the brown part, closer to the pictorial layer, additional amino acid fragments are detected: $\mathrm{C}_{3} \mathrm{H}_{9} \mathrm{~N}_{3}{ }^{+}, \mathrm{C}_{4} \mathrm{H}_{10} \mathrm{~N}_{3}{ }^{+}, \mathrm{C}_{5} \mathrm{H}_{8} \mathrm{~N}_{3}{ }^{+}$(arginine fragments), $\mathrm{C}_{8} \mathrm{H}_{10} \mathrm{~N}^{+}$and $\mathrm{C}_{8} \mathrm{H}_{10} \mathrm{NO}^{+}$, respectively phenylalanine and tyrosine fragments, originating also from an animal glue. In Figure $5 b$, the detection of phosphate ions, which are shown in red (mostly in the upper right part of the figure, named above the brown part), is intriguing. Although this could be the result of fragmentation of phospholipids, but in that case fatty acids should also be detected, a possible hypothesis is that this is due to a bacterial degradation of the organic components, or leaching of calcium phosphate or a thermal degradation after a previous relining.
Paint layer. According to contemporary sources, the two paintings were painted "a guazzo", 9 a technique that refers to both glue-based paint and egg-tempera. Therefore we looked for the ions characteristic of animal glue or egg. Fatty acids are detected in negative ion mode and are evidence of the presence of triglycerides and/or phospholipids from oil and egg yolk, respectively. In positive ion mode, proteins are detected through their amino acid fragments. Their detection vouches for the presence of glue or egg yolk or egg white. Figure 6 summarizes this information.

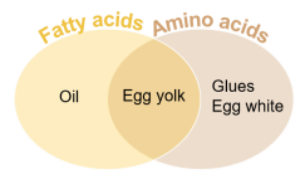

Figure 6: Schematic representation of the distinction between binders according to the detected ions: if fatty acids are detected in negative ion mode, the binder can be oil or egg yolk-based, and if amino-acid fragment ions are detected in positive ion mode, the binder can be glue or egg-based. If both species are detected, the binder can be egg yolk or mixtures.

If glue is the binder, it would then be found both in the preparation layer (and the lining) and in the painting layer. Egg white can be identified by comparing the detected amino acid fragments with those of albumin. In contrast, egg yolk contains proteins and several lipids (Table S5 and Figure S6), including phosphatidylcholine, as characteristic fragments of glycerophospholipids $\left(\mathrm{C}_{5} \mathrm{H}_{15} \mathrm{NPO}_{4}{ }^{+}, \quad m / z 184.1 ; \mathrm{C}_{8} \mathrm{H}_{19} \mathrm{NPO}_{4}^{+}, \quad m / z\right.$ 224.1) and cholesterol (characteristic ions $\mathrm{C}_{27} \mathrm{H}_{45} \mathrm{O}^{+}, \mathrm{m} / z, 385.3$ and $\mathrm{C}_{27} \mathrm{H}_{45}{ }^{+}, \mathrm{m} / z$ 369.4). ${ }^{17}$ The amino acids fragments are detected around the fibres and in the thin surface layer, but not in the pigment layers. Therefore, glue or egg white are unlikely to be binding this layer. Moreover, the characteristic ions of the egg yolk are not detected in the mass spectra, neither from the dual beam analysis nor from the acquisitions on small areas, suggesting the absence of egg yolk as well.

In the spectra recorded during dual beam BA+DE analyses, there is almost no detection of fatty acids. Only a weak signal is detected in the area where PDMS is detected, which could correspond to a poorly cleaned area. The absence of detection of lipids indicates again that the binder is unlikely to be egg yolk, and suggests that it is not oil either. However, the absence of both signals corresponding to fragments of amino acids and fatty acids in the green layer is doubtful.

The spectra recorded in HCBU mode provide additional information. Fatty acids are detected, after cleaning of the surface, but only by tuning the surface potential compensation specifically for the green layer. Without this modification, fatty acids were hardly detected. Two hypotheses follow from this. First, the spectrum in dual beam BA+DE mode was recorded after cleaning with argon and with a gentle cleaning between each analysis scan. It is therefore possible that the cleaning with argon clusters sputtered away the organic compounds in the green layer, to the benefit of many inorganic compounds. This is consistent with the weak detection of ions at $\mathrm{m} / \mathrm{z}, 255$ and $\mathrm{m} / \mathrm{z}, 283$ in the very first scans of the analysis. This is not observed for the fibres, the resin and the thin surface layer which are almost composed only of organic compounds. Thus, during the analysis, the ion signals detected from the green layer were only coming from the compounds not sputtered by the argon clusters. As 
explained before, this leads to a difference in height between layers at the end of the acquisition (observable with an optical microscope), and explains the loss of signal depending on the secondary ion extraction parameters, simply because all the layers are not anymore at the same height (Figure 3). The lipids detected in $\mathrm{HCBU}$ can then originate from an improperly cleaned surface contamination, because of this difference in height. Secondly, the difference in detection, according to the value of surface potential correction in HCBU having been made on a newly polished surface, indicates that the cleaning modifies the surface potential of the surface. Therefore, this must be also taken into account. The recording of smaller images in BA+DE mode, made with specific surface potential corrections retuned in each case, is therefore mandatory if one is to reach a conclusion on the nature of the binder. Doing so, fatty acids are indeed detected (Figure 7). Finally, the sample prepared with the microtome gave even better images, thanks to improved planarity, allowing one to distinctively perceive the shape of the layer. It should also be noted that the samples prepared by dry polishing also gave adequate results.
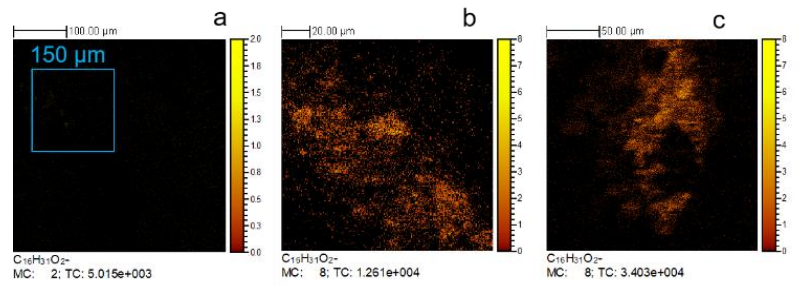

Figure 7: Ion images of the of the palmitate ion $\mathrm{C}_{16} \mathrm{H}_{31} \mathrm{O}_{2}{ }^{-}, m / z$ 255.2, recorded with different analytical conditions (see Figure S9 for localisation on the sample surface). a: dual beam depth profiling on the whole sample, area $400 \mu \mathrm{m} \times 400 \mu \mathrm{m}, 1024 \times 1024$ pixels, pixel size $390 \mathrm{~nm}$, colour scale intensity 2 (MC), recorded in area a (see Figure S9). The blue square shows the area chosen for the ion image shown in b; b: settings locally adapted on a dry-polished sample surface, area $150 \mu \mathrm{m} \times 150 \mu \mathrm{m}, 256 \times 256$ pixels, pixel size $590 \mathrm{~nm}$, colour scale intensity 8 (MC), recorded in area b (see Figure S9); c: settings locally adapted on a microtome-cutted (tungsten blade) sample surface, area $200 \mu \mathrm{m} \times 200 \mu \mathrm{m}, 512 \times 512$ pixels, pixel size $390 \mathrm{~nm}$, colour scale intensity 8 (MC), recorded in area c (see Figure S9).

In summary, the dual beam images of the whole sample surface in $\mathrm{BA}+\mathrm{DE}$ mode indicated no clear detection of amino acid fragments, but also no fatty acids in the pigmented layer, while the first were detected in other layers and the latter in the pigmented layer in HCBU mode. The dual beam BA+DE images alone, without considering the heterogeneous extraction of the secondary ions, could have led to conclude that the Infant Bacchanals were indeed painted "a guazzo", based on the absence of detection of oil. However, in the small BA+DE images, fatty acids are detected without any ambiguity. Contrary to expectation, the binder is oil. In this sample, the painting technique is therefore not "a guazzo".

Pigments identified in the green layer. The following section presents the different pigments identified in the Pp1 sample, by comparing the detected ions peaks with those from reference mass spectra recorded in the laboratory on pure pigments from Kremer Pigmente $\mathrm{GmbH}$ (see supporting information Figures S10 to S19 and Tables S7 and S8).
The detection of $\mathrm{Al}^{+}, \mathrm{Si}^{+}, \mathrm{Fe}^{+}, \mathrm{Mg}^{+}$and $\mathrm{K}^{+}$ions in several round shaped areas indicates a green earth, as previously observed on Poussin paintings. ${ }^{18,19}$ It is a natural mineral green pigment, composed of celadonite $\mathrm{K}(\mathrm{Mg}, \mathrm{Fe})(\mathrm{Fe}, \mathrm{Al})\left[\mathrm{Si}_{4} \mathrm{O}_{10}\right](\mathrm{OH})_{2}$ and/or glauconite $(\mathrm{K}, \mathrm{Na})\left(\mathrm{Fe}^{\mathrm{III}}, \mathrm{Al}, \mathrm{Mg}\right)_{2}\left[\left(\mathrm{Si}, \mathrm{Al}, \mathrm{Fe}^{\mathrm{III}}\right)_{4} \mathrm{O}_{10}\right](\mathrm{OH})_{2}$, depending on the geological origin. Large dark green particles with very precise edges are visible, in a lighter green mixture. A region of interest (ROI 1) has been drawn around these particles, and the spectrum extracted from this ROI was then compared to reference spectra of celadonite and glauconite minerals (Figure S20). The mass spectrum from ROI 1 contains intense ion peaks assigned to $\mathrm{Fe}_{2}{ }^{+}, m / z, 111.9, \mathrm{Fe}_{2} \mathrm{O}^{+}, m / z, 127.9, \mathrm{Fe}_{2} \mathrm{O}_{2}{ }^{+}$, $m / z$ 143.9, $\mathrm{SiOFe}^{+}, m / z$ 99.9, and $\mathrm{FeOSiO}_{2} \mathrm{H}^{+}, m / z$ 132.9, similarly to the spectrum of glauconite, even if the two reference minerals mass spectra are close. However, according to Fanost, et al. the garland contains a celadonite-rich green earth. ${ }^{19}$ Therefore, either Poussin used two kinds of green earth in the painting depending on the area, or TOF-SIMS would not be able to distinguish between glauconite and celadonite in mixtures.

The rest of the layer is a green-yellow mixture containing many pigment particles. Several ROIs were drawn around each to extract the associated mass spectra, in positive and negative ion modes. The extracted mass spectra were then compared to the reference mass spectra made with the pigments from Kremer Pigmente. We can list the identification of bone black (calcium phosphate rich charred animal bone) through the ion peaks assigned to $\mathrm{PO}_{2}(\mathrm{CaO})_{\mathrm{n}}{ }^{+}(\mathrm{n}=1-7)$; Naples Yellow $\left(\mathrm{Pb}_{3}\left[\mathrm{SbO}_{4}\right]_{2}\right)$ through the ion peaks assigned to $\mathrm{Pb}_{n} \mathrm{SbO}_{\mathrm{m}}{ }^{+}(\mathrm{n}=1-3 ; \mathrm{m}=1-4)$; Smalt (CoOKSi glass, with $\mathrm{Ni}$ impurities) by detection of ion peaks assigned to $\mathrm{Co}^{+}, \mathrm{CoOH}^{+}$and $\mathrm{Ni}^{+}$; lead based pigment and iron based red pigment, which is probably red ochre. Some particles are rich in As and are likely to be orpiment $\left(\mathrm{As}_{2} \mathrm{~S}_{3}\right)$. All of the images and spectra are shown in Figures S21 and S22.

These results are entirely consistent with the mixed green used by Poussin which referred to as a "Claude mixture", named after the painter Claude Gellée, known as "le Lorrain" (Chamagne, around 1600 - Rome, 1682), who was a close friend of Poussin. It is actually a mixture of many green, black, yellow, white and blue pigments. Burnstock lists the presence of the following pigments in the mixture (not all need to be present): green earth, lead white, yellow and red ochre, umber, bone black, charcoal, chalk, quartz, copper green (verditer, malachite, verdigris), ultramarine, smalt, lead tin yellow, Naples yellow. ${ }^{20}$ In this work, calcium carbonate has also been detected in the green layer, as seen in Figure $8 b$.

The study of the ion image of the $\mathrm{Ca}^{+}$ion enables to isolate a particularly large particle rich in calcium (Figure S21a), and to draw ROI 2 around this area in order to extract the corresponding mass spectrum (Figure $\mathrm{S} 21 \mathrm{~b}$ ). A series of $\mathrm{Ca}_{\mathrm{n}} \mathrm{O}_{\mathrm{m}} \mathrm{PO}_{2}{ }^{+}$ions $(\mathrm{n}=\mathrm{m}=1-6$ and $\mathrm{n}=1-6, \mathrm{~m}=\mathrm{n}-1)$ is detected, which is characteristic of calcium phosphate contained in bone black, according to the corresponding reference mass spectrum (Figure S21c). Bone black mixed with As-S containing compound and a green earth is likely. However, the comparison with the reference spectra of orpiment and realgar was inconclusive. The pigment in the cross-section is probably degraded in an arsenic oxide and therefore very different from the modern references.

The identification of Naples yellow (lead antimoniate) $\mathrm{Pb}_{3}\left(\mathrm{SbO}_{4}\right)_{2}$ is clear, even if it might be mixed with an Sn containing pigment (Figure S22). 

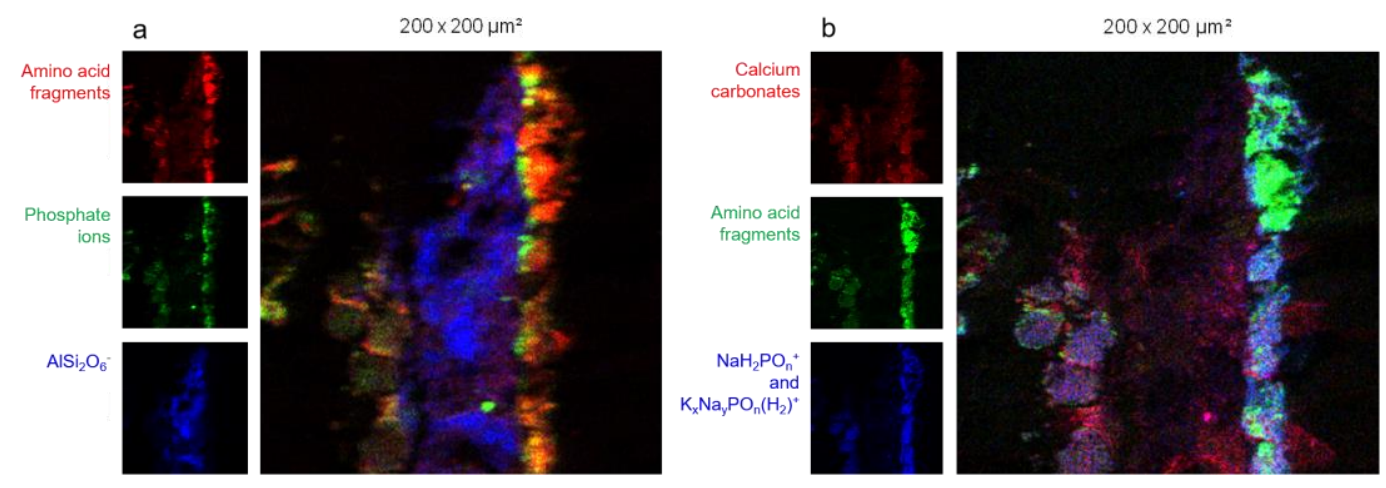

Figure 8: a: Three-colour overlay between ion images of phosphates (green), amino acid fragments (red), and an aluminosilicate fragment ion $\mathrm{AlSi}_{2} \mathrm{O}_{6}{ }^{-}, \mathrm{m} / z .172 .92$ (blue), all recorded in negative polarity. Image size $200 \mu \mathrm{m} \times 200 \mu \mathrm{m}$. b: Three-colour overlay between ion images of sum of ion images of calcium carbonate ions (red), amino acid fragments (green), and sum of characteristic inorganic ions from egg white (Figure S7) $\mathrm{NaH}_{2} \mathrm{PO}_{n}{ }^{+}(\mathrm{n}=1-4), \mathrm{K}_{x} \mathrm{Na}_{y} \mathrm{PO}_{n}\left(\mathrm{H}_{2}\right)^{+}(\mathrm{x}=0-2 ; \mathrm{y}=3-0 ; \mathrm{n}=3-4)$ (blue), all recorded in positive polarity. Image size $200 \mu \mathrm{m} \times 200$ $\mu \mathrm{m}$. See Figure $\mathrm{S} 9$ for localisation on the sample surface. Images recorded in area $\mathrm{d}$ (see Figure $\mathrm{S} 9$ ).

Aluminum is present in the earth, but also in mordants for lakes. Some very small particles are rich in aluminum, but are not a green earth large particle. An ROI was drawn around such a little particle to see if any organic molecule was localized here. We are looking for instance for a yellow lake, fixed on chalk or alumina. However, the size of the particle gives a reconstructed spectrum of very low intensity, overwhelmed by lead oxide ion peaks (Figure S23).

Fine organic top layer. Fragments of lysine, isoleucine and possibly proline (Table S2) are detected in the thin layer at the surface of the painting layer. This could indicate the presence of albumin from egg white. Some of the amino-acid fragment ions detected in this layer are also detected in the fiber layer, at $m / z$. $56.05\left(\mathrm{C}_{3} \mathrm{H}_{6} \mathrm{~N}^{+}\right), m / z 84.09\left(\mathrm{C}_{5} \mathrm{H}_{10} \mathrm{~N}^{+}\right), m / z 86.11\left(\mathrm{C}_{5} \mathrm{H}_{12} \mathrm{~N}^{+}\right)$, $m / z 98.09\left(\mathrm{C}_{6} \mathrm{H}_{12} \mathrm{~N}^{+}\right), m / z, 22.97\left(\mathrm{Na}^{+}\right), m / z, 70.03\left(\mathrm{C}_{3} \mathrm{H}_{4} \mathrm{NO}^{+}\right)$, and $m / z, 70.07\left(\mathrm{C}_{4} \mathrm{H}_{8} \mathrm{~N}^{+}\right)$.

In the optical image, it seems that the deeper part of this top layer is whiter than the outmost part. It could be linked to the higher resin penetration at the very top. However, a three colour-overlay in negative ion mode between the sum of amino acid fragment ions and the phosphate ions, shows that the amino acids are located at the top while phosphates are detected at the border between the fine layer and the green pigmented one underneath (Figure 8a). In the positive ion mode, the layer is not homogeneous. The amino acids fragments are mostly located in top part while an ROI drawn around the deeper part brings out inorganic ions detected in the egg white reference spectrum (Figure S7), and that share the localisation of the phosphate ions in negative polarity (Figures 8a and b). Then it could mean that a fine layer containing egg white is superimposed onto a thicker layer containing phosphates, which could be remains of egg yolk. Egg white was indeed commonly used as a temporary varnish, a protective layer. However, it should be kept in mind that this layer can be the result of a degradation (with characteristic peaks of $\mathrm{Na}, \mathrm{K}$, or oxalates), or a relining by animal glue, or even a residue of varnish.

The "Big Bacchanal" sample Pg3. This second sample is very rough with an unclear stratigraphy (Figure 1d), and the recorded data are very difficult to understand. However it must be noticed that the previous conclusions about the sample preparation step, the reduction of size of the analysed areas with the local tuning of the analyser settings are also available with this sample, even if its composition gives it a gravelly and rough surface. In the preparation layer, and even if its shape is difficult to understand, areas sharing the same composition as the preparatory layer of Pp1 sample are found. This is consistent with a closeness in time and technique between the two paintings. In the pigmented layer, fatty acids were also detected, making the two Bacchanal paintings apparently not "a guazzo". Exactly as for Pp1, using the dual beam analysis alone would have led to the erroneous conclusion of the absence of fatty acids. Here, without a clear visualization of the stratigraphy as in $\mathrm{Pp} 1$, it would have been very conceivable to conclude to a glue or an egg binder, because amino acids were detected. This demonstrates the complementarity of imaging techniques to bulk analyses. The roughness of this second sample makes the TOF-SIMS analysis rather unsuitable to identify small particles, as opposed to SEM.

\section{CONCLUSION}

Contrary to what might have been expected, the two Infant Bacchanals painted by Nicolas Poussin at a very early stage of his Roman career are not "a guazzo", that is, they are both executed with an oil binder. TOF-SIMS imaging revealed to be a valuable tool extracting this information, since it can map both organic and inorganic compounds, with known characteristic ions for each type of binder, amino- and fatty acids. The chalky unsaturated finish of the colours could be the result of a thin protein layer on the surface of the painting, containing egg white characteristic ions, or maybe the result of the absorbency of the ground layer, perhaps more likely if one considers the highly porous nature of the paint layers. These conclusions must however be circumscribed because only two samples were analysed, even if these come from two paintings having been painted by the artist with the same technique and at the same time.

The structure of the painting made of a layered heterogeneous mixture of several organic and mineral compounds brought analytical difficulties. Not only because its roughness and heterogeneity in composition, but also because its physical behaviour during the analysis. It was then necessary to tune the instrument in accordance with each layer in order not to lose any part of the signal: the GCIB is a very useful tool to clean the samples and 
to improve the contrast of images, enabling the localization and identification of micrometric pigment particles. Many pigments were found in the pigment layer, which is consistent with the use of a "Claude mixture". However, when it comes to organic materials, the unevenness of the sputtering can lead to analysis artefacts. Our results suggest that the microtome cutting preparation of the sample surface remains the best way to get high quality ion images and mass spectra.

\section{ASSOCIATED CONTENT}

The Supporting Information is available free of charge.

Tables S1-S8 and Figures S1-S23: details of sample preparation, mass spectra of reference compounds, tables of detected ions in the samples and in the reference compounds.

\section{REFERENCES}

(1) Keune, K.; Boon, J.J. Imaging Secondary Ion Mass Spectrometry of a Paint Cross Section Taken from an Early Netherlandish Painting by Rogier van der Weyden. Anal. Chem. 2004, 76, 1374-1385.

(2) Keune, K.; Boon, J.J. Analytical Imaging Studies Clarifying the Process of the Darkening of Vermilion in Paintings. Anal. Chem. 2005, 77, 4742-4750.

(3) Sanyova, J.; Cersoy, C.; Richardin, P.; Laprévote, O.; Walter, P.; Brunelle, A. Unexpected Materials in a Rembrandt Painting Characterized by High Spatial Resolution Cluster-TOF-SIMS Imaging. Anal. Chem. 2011, 83, 753-760.

(4) Richardin, P.; Mazel, V.; Walter, P.; Laprévote, O.; Brunelle, A. Identification of Different Copper Green Pigments in Renaissance Paintings by Cluster-TOF-SIMS Imaging Analysis. J. Am. Soc. Mass Spectrom. 2011, 22, 1729-1736.

(5) Mazel, V.; Richardin, P. ToF-SIMS study of organic materials in Cultural Heritage: identification and chemical imaging. In Organic Mass Spectrometry in Art and Archaeology; Colombini, M.P.; Modugno, F., Eds; Wiley, 2009, pp 433-458.

(6) Noun, M.; Van Elslande, E.; Touboul, D.; Glanville, H.; Bucklow, S.; Walter, P.; Brunelle, A. High mass and spatial resolution mass spectrometry imaging of Nicolas Poussin painting cross section by cluster TOF-SIMS. J. Mass Spectrom. 2016, 51, 1196-1210.

(7) de Viguerie, L.; Walter, P.; Glanville, H. Some preliminary remarks on Nicolas Poussin's painting technique in L'Orage: complementary X-ray fluorescence/X-ray diffraction study. Kermes 2015 94/95, 97106.

(8) Rosenberg, P. Nicolas Poussin, Les tableaux du Louvre, Catalogue raisonné; Louvre Editions/Somogy: Paris, 2015.

(9) Bellori, G. P. Le vite de' pittori, scultori e architettimoderni; Marcadi: Rome, 1672.

(10) Mazel, V.; Richardin, P.; Touboul, D.; Brunelle, A.; Walter, P.; Laprévote, O. Chemical imaging techniques for the analysis of complex mixtures: New application to the characterization of ritual matters on African wooden statuettes. Anal. Chim. Acta 2006, 570, 34-40.

(11) Vanbellingen, Q.P.; Elie, N.; Eller, M.J.; Della-Negra, S.; Touboul, D.; Brunelle, A. Time-of-flight secondary ion mass spectrometry

\section{AUTHOR CONTRIBUTION:}

C.B. designed the study, performed experiments and data analysis, and wrote the main manuscript. H.G., L.d.V. and C.M. assisted with experimental design and writing of the manuscript. H.G. and C.M. took the samples from the paintings. P.W. designed the study and wrote the main manuscript. A.B. designed the study, assisted in experiments and data analysis, and wrote the main manuscript.

\section{NOTES}

The authors declare no competing conflict of interest.

\section{ACKNOWLEDGMENTS}

This work was financially supported by the Agence Nationale de la Recherche (grant ANR-2015-CE29-0007 DEFIMAGE). The authors would like to thank Rémi Brageu (LAMS) for his help in processing photographs used.

imaging of biological samples with delayed extraction for high mass and high spatial resolutions. Rapid Commun. Mass Spectrom. 2015, 29 , $1187-1195$.

(12) Seyer, A.; Einhorn, J.; Brunelle, A.; Laprévote, O. Localization of Flavonoids in Seeds by Cluster Time-of-Flight Secondary Ion Mass Spectrometry Imaging. Anal. Chem. 2010, 82, 2326-2333.

(13) Vermeulen, M.; Poleunis, C.; Delcorte, A; Bertrand, P; Sanyova, $\mathrm{J}$. The use of argon cluster bombardment for the surface preparation of paint cross-sections for analysis by ToF-SIMS: Surface preparation with argon cluster ion beams. Surf. Interface Anal. 2014, 46, 781-785. (14) Kawecki, M.; Bernard, L. Database of proteinogenic amino acid reference spectra for Bismuth-cluster ToF-SIMS. II. Positive polarity Surf. Sci. Spectra 2018, 25, 015002.

(15) Taylor, M.J.; Zhang, K.Y.; Graham, D.J.; Gamble, L.J. Fatty acid and lipid reference spectra. Surf. Sci. Spectra 2018, 25, 025001.

(16) Sanni, O.D.; Wagner,M. S.; Briggs, D.; Castner, D.G.; Vickerman, J. C. Classification of adsorbed protein static ToF-SIMS spectra by principal component analysis and neural networks. Surf. Interface Anal. 2002, 33, 715-728.

(17) Benetti, F.; Perra, G.; Damiani, D.; Atrei, A.; Marchettini, N. ToFSIMS characterization of proteinaceous binders in the wallpainting "Madonna and Child enthroned with Saints" by AmbrogioLorenzetti in the St. Augustine Church (Siena, Italy). Int. J. Mass Spectrom. 2015, 392, 111-117.

(18) Glanville, H.; Seccaroni, C. Kermes 94/95: Nicolas Poussin, Technique Practice Conservation; 2015; 27, pp. 4-131.

(19) Fanost, A.; Gimat, A.; de Viguerie, L.; Martinetto, P.; Giota, A.C.; Clemancey, M.; Blondine, G.; Gaslain, F.; Glanville, H.; Walter, P.; Meriguet, G.; Rollet, A.-L.; Jaber, M. Revisiting the identification of commercial and historical green earth pigments. Colloid Surface A. 2020, 584, 124035 .

(20) A. Burnstock, « The application of scanning electron microscopy (SEM) to the examination of painting materials with special reference to cleaning and blanching », 1991. Thesis (Ph. D.)--University of London, 1991. In 2 vols. 


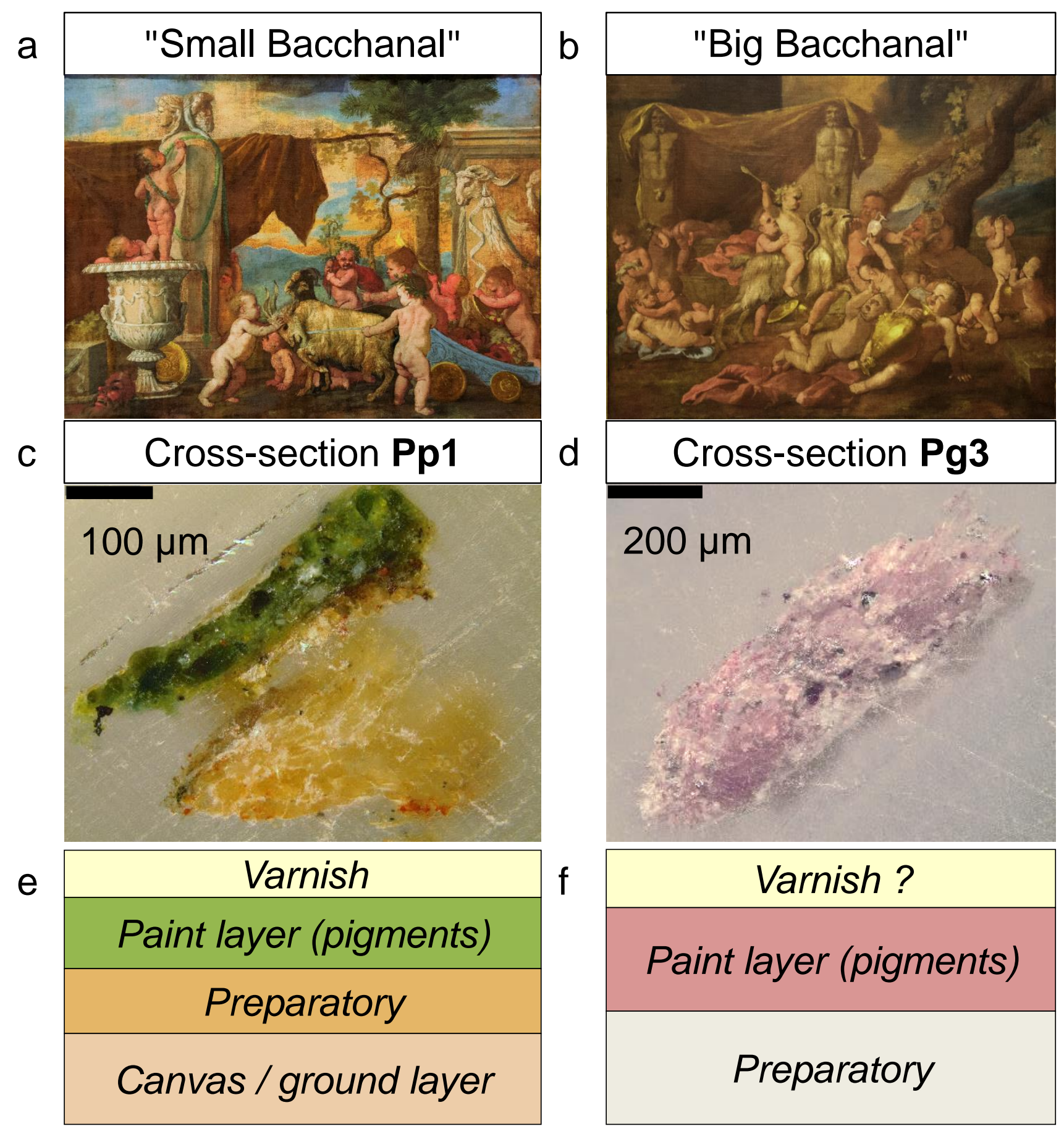

Figure 1 


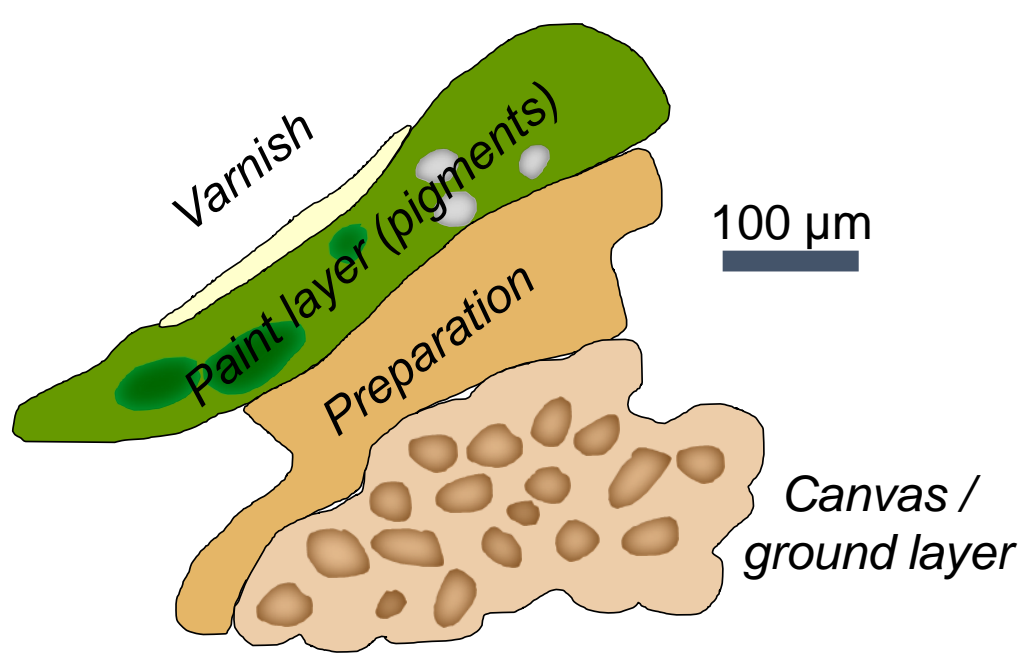

Figure 2 


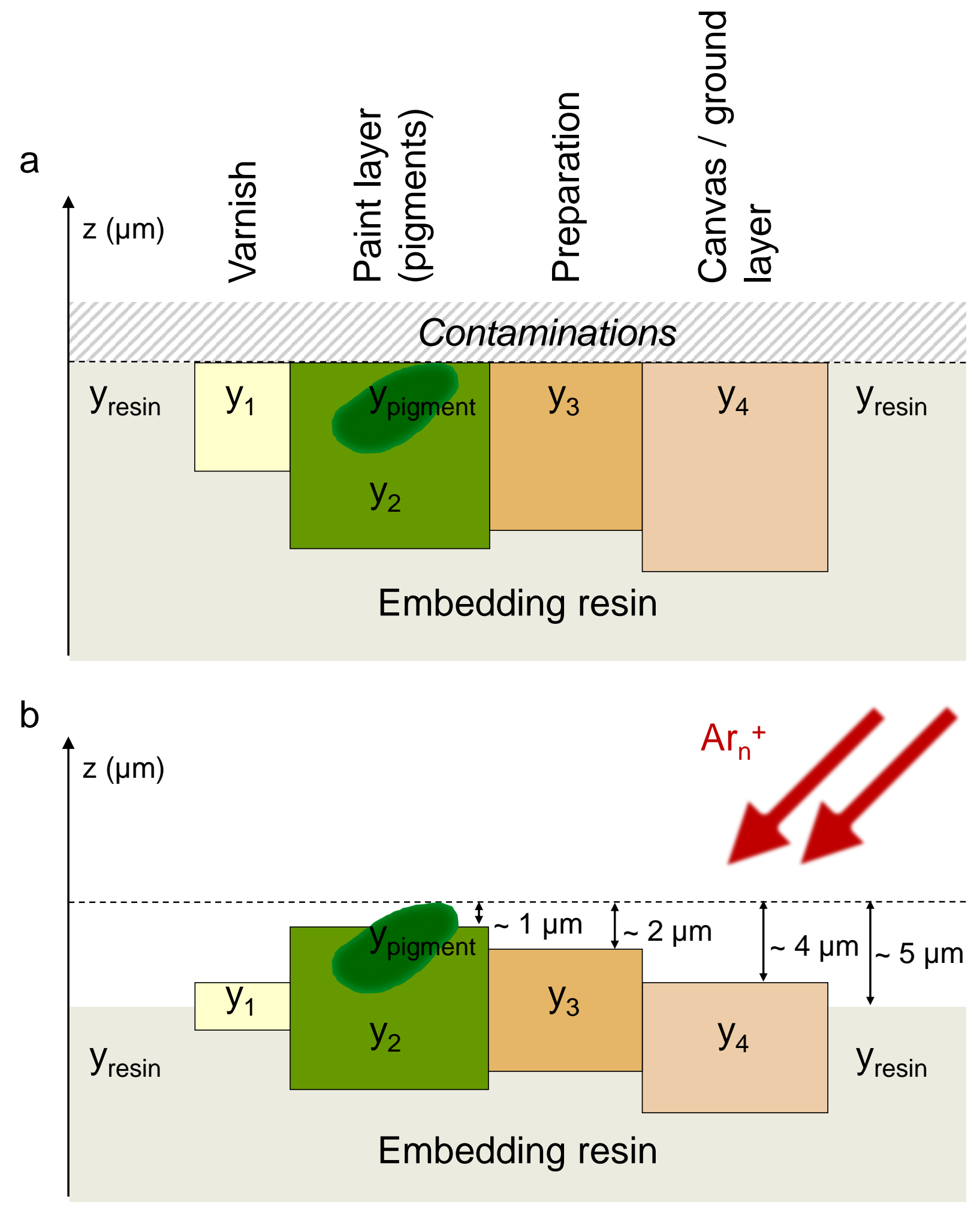

Figure 3 


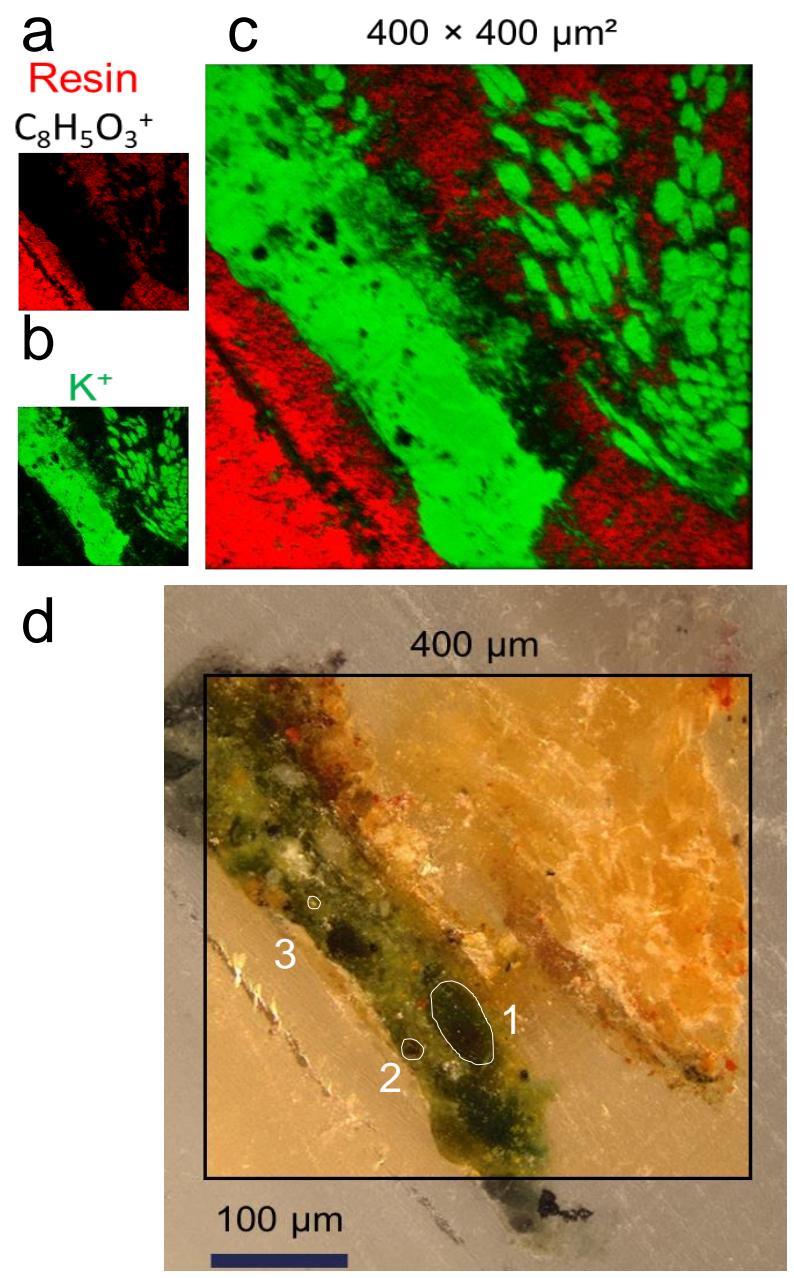

Figure 4 
a

Ca carbonates

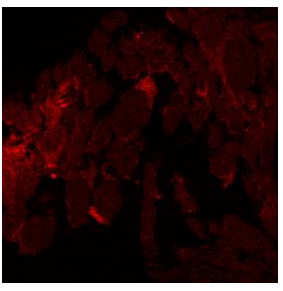

Amino acid fragments

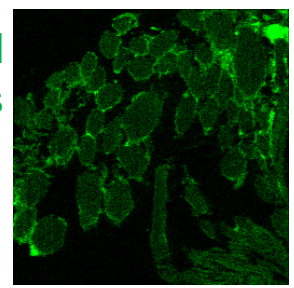

$\mathrm{C}_{4} \mathrm{H}_{5} \mathrm{O}_{2}+$

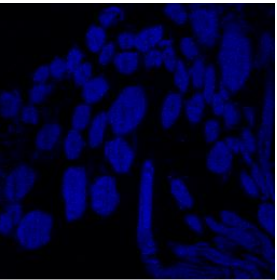

b

Phosphate ions

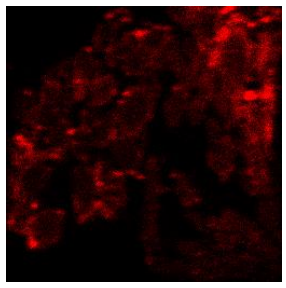

Amino acid fragments

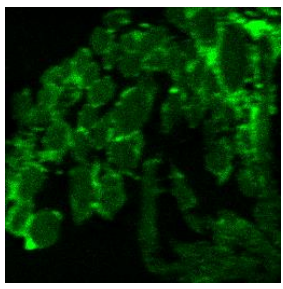

$\mathrm{CHO}_{2}$

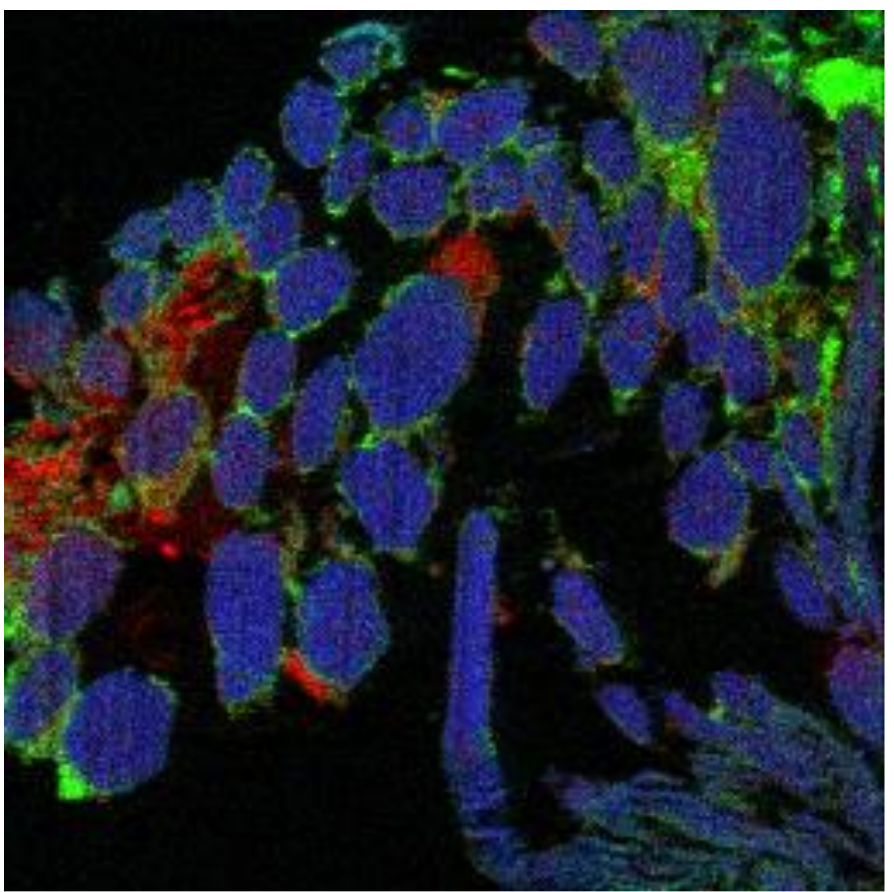

$200 \times 200 \mu \mathrm{m}^{2}$

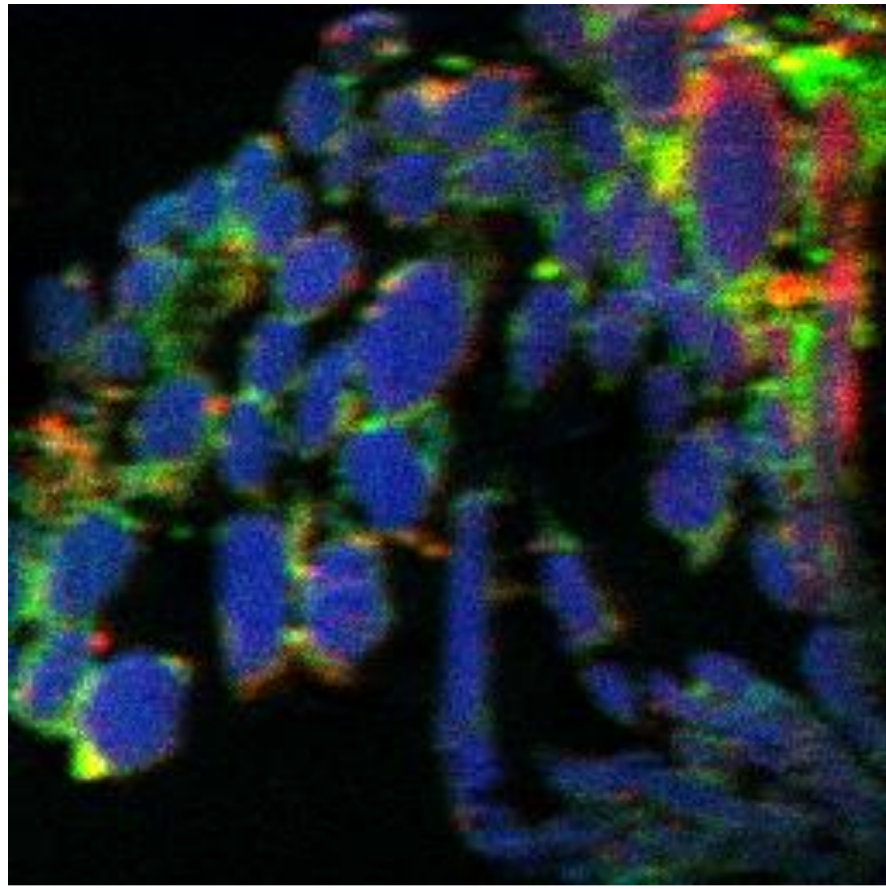

Figure 5 


\title{
Fatty acids Amino acids
}

\author{
\begin{tabular}{ll|l} 
Oil Egg yolk & $\begin{array}{l}\text { Glues } \\
\text { Egg white }\end{array}$
\end{tabular}
}

Figure 6 

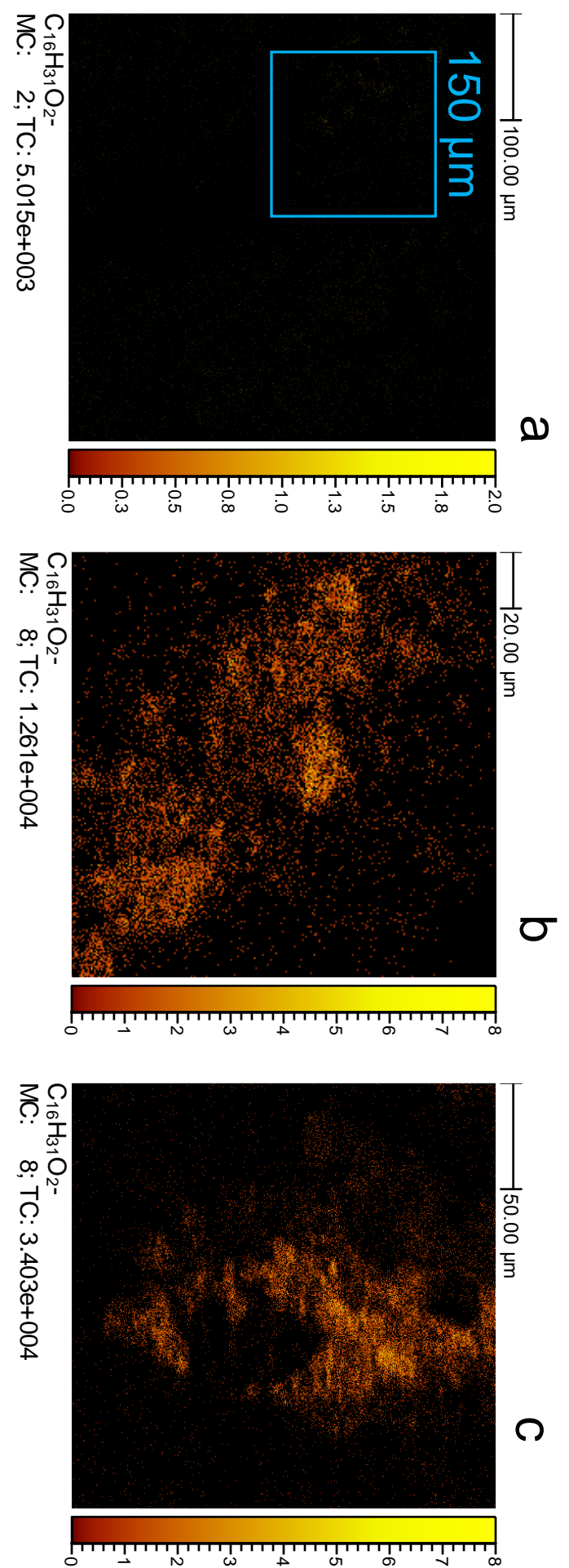

Figure 7 


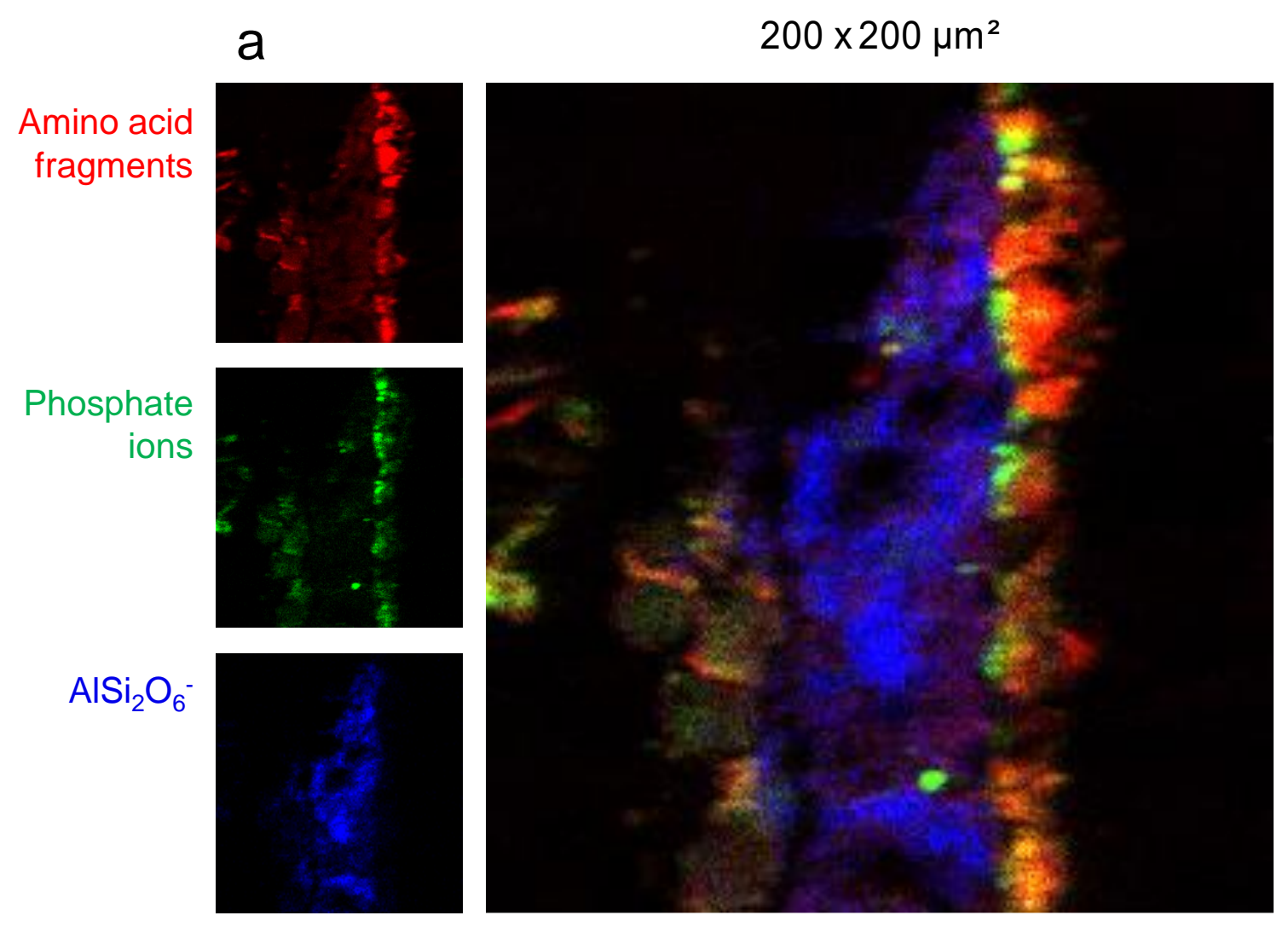

Figure 8 


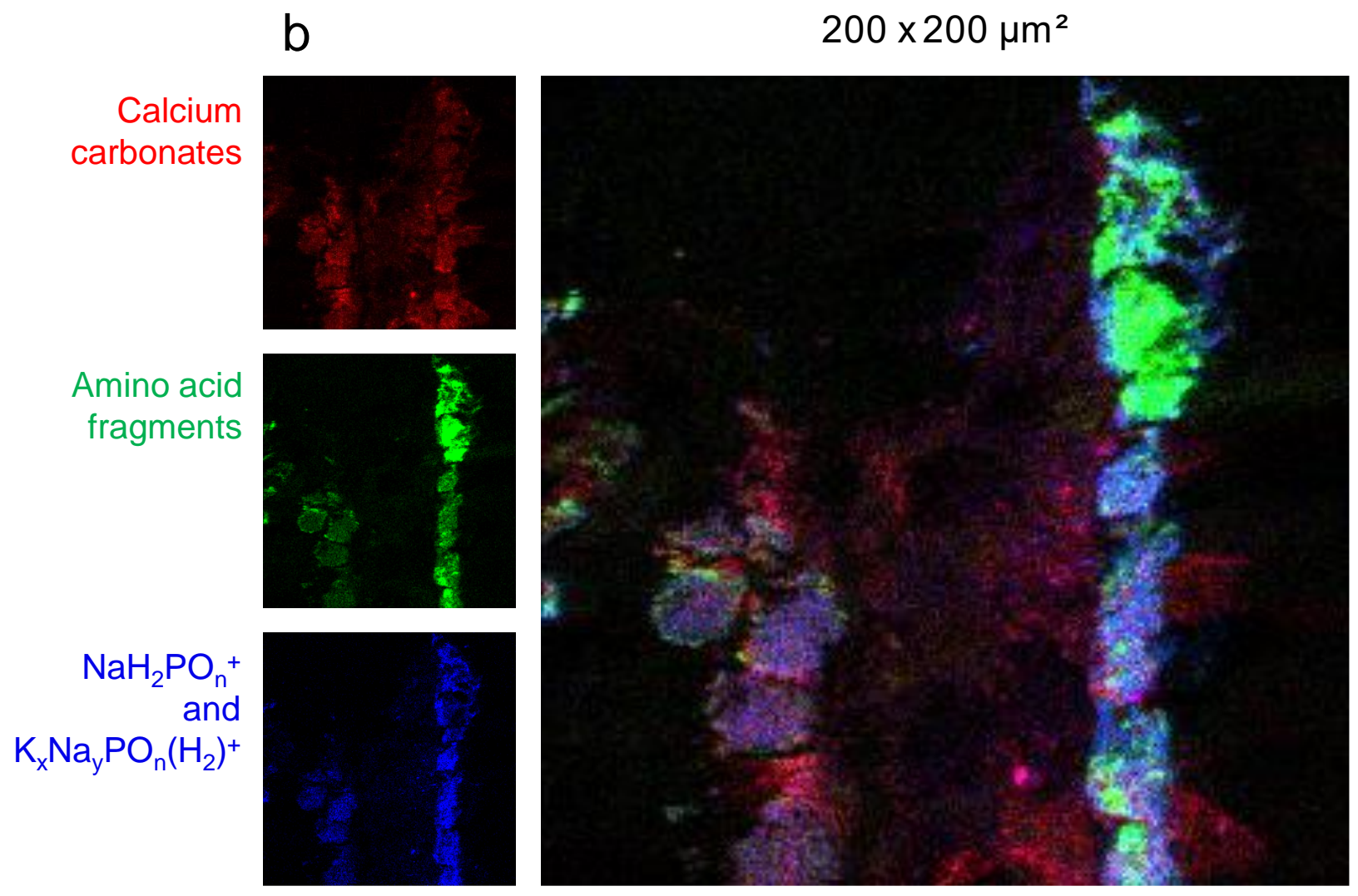

Figure 8 